\title{
A Mechanistic Approach to Topsoil Damage due to Slip of Tractor Tyres
}

\author{
Andrea Battiato ${ }^{* 1}$, Etienne Diserens ${ }^{2}$, Lyesse Laloui $^{3}$, Luigi Sartori ${ }^{4}$ \\ ${ }^{1,2}$ Agroscope Reckenholz-Tänikon ART Research Station, CH-8356 Ettenhausen, Switzerland \\ ${ }^{3}$ Laboratory of Soil Mechanics EPFL-ENAC-LMS, Station 18, CH-1015 Lausanne, Switzerland \\ ${ }^{4}$ Department of Land, Environment, Agriculture and Forestry T.e.S.A.F., University of Padua, Agripolis, Viale dell’Università \\ 16, 35020 Legnaro, Padua, Italy \\ *1 andrea.battiato@agroscope.admin.ch; andreas.battiato@gmail.com
}

\begin{abstract}
ABST RACT
High slip of tractor traction tyres causes topsoil damage in terms of soil cutting effect with the formation of a strengthless layer strongly exposed to erosion and an underlying layer where shear deformations contribute to the alteration of soil structure functionalities. The cutting effect is clearly indicated by longitudinal topsoil shear displacement. In spite of a recognized need for limiting the slip of tractor ty res, no theoretical approaches have been presented so far to indicate a range where no topsoil damage occurs. In this paper mechanical conditions along the soil-ty re contact surface which lead to topsoil cutting were analy sed with a soil-tyre interaction model and discussed on the basis of traction tests with a MFWD tractor on an agricultural silt loam Calcaric Fluvisol. The lon gitudinal top soil shear displacement was measured for a slip ranging between $5 \%$ and $48 \%$. An evident topsoil failure took place as soon as the shear stress along the soil-tyre contact approached the soil strength. Values of slip at which this condition was reached were identified for three tractor configurat ions. These slip values should be regarded as indicative limits not to be exceeded in tillage operations in order to avoid topsoil damage in the conditions considered.
\end{abstract}

Key words: top soil displacement; traction performance; soil-ty re interaction model; wheel slip.

\section{INTRODUCTION}

Tractor traction tyres interact with soil by a system of normal and tangential stresses along the soil-tyre contact surface. In this interaction both soil and tyre deform according to their own stress-strain relationships. Soil deformation results in the formation of a rut as well as in topsoil dis placement along the soil-tyre contact surface. The topsoil displacement depends on shear stress which soil undergoes at contact with tyre. The shear stressdisplacement relationship characterizing the soil layer which interacts with the traction tyre has been studied for a long time as it strongly affects the relationship between traction force and wheel slip, usually referred to as traction performance of the soil-wheel system (Becker, 1956; Janosi and Hanamoto, 1961; Wills, 1963; Wong and PrestonThomas, 1983)

High traction forces are obtained by mobilizing the strength of soil elements among tyre lugs, so it follows that they mainly depend on the strength of the soil which interacts with the tyre tread rather than on tyre material-soil interfacial resistance (Yong et al., 1984). As soon as the whole strength is mobilized, the soil elements among tyre lugs fail (soil cutting) with the consequent formation of a strengthless layer (fig. 1) and an underly ing layer which shows high shear deformations.

The soil strength has long been recognized as one of the main factors limiting soil erosion processes (Fan and $\mathrm{Wu}$, 2001; Nearing and West, 1988; Watson and Laflen, 1986). Effects of shear deformations on soil structure with regard to the alteration of the pore system functionalities have been pointed out by different researchers (Kirby, 1991; O’Sullivan et al., 1999).

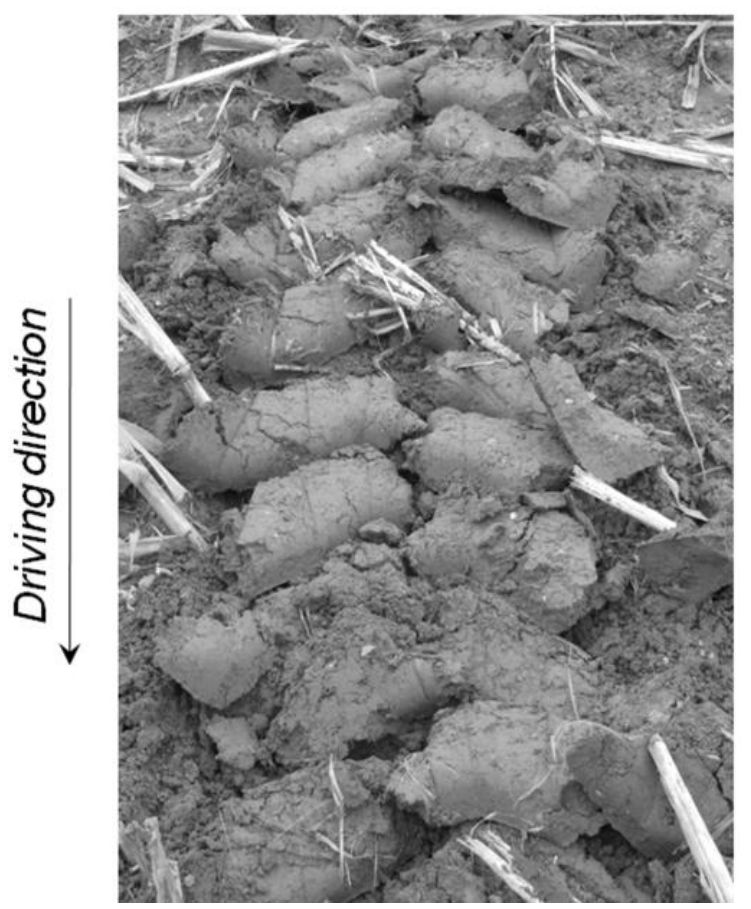

Figure 1. Example of soil cutting with a residual strength less layer exposed to erosion in an agricultural silt loam (SiL) Calcaric Fluvisol with maize stubble.

Shear deformations have been proved to affect air permeability (Kirby, 1991; O’Sullivan et al., 1999) and gas diffusivity (O’Sullivan et al., 1999) in soil samples. The role of shearing, in addition to vertical compaction, in soil 
homogenisation and particle rearrangement with reduction of hydraulic conductivity was described by Horn (2003). More recently, also Alaoui et al. (2011) and Berisso et al. (2013) remarked the influence of shear stress-strain due to traffic of agricultural vehicles on the alteration of: the soil pore system, the soil hydraulic properties such as soil water retention curve and unsaturated hydraulic conductivity (Alaoui et al., 2011), and the air permeability and pore continuity (Berisso et al., 2013).

Moreover, the slip has been recognized to contribute in causing soil compaction pointed out by increased soil density (Raghavan et al., 1977; Raghavan et al., 1978), whereas Davies et al. (1973) showed how wheel slip is more important in causing compaction than additional wheel loading.

The remarkable influence of shear stress at wheel-soil interface on the magnitude of the major principal stress in the upper soil layer was pointed out by Olsen (1988). He also reported experimental results showing an increase in soil density due to the application of shear stress and observed shear strain under a simple shear plate in the upper $2 \mathrm{~cm}$ of soil below the plate.

Issues concerning topsoil da mage due to tyre slip should be taken into account and further investigated (Diserens and Battiato, 2012). Although the slip is strictly related to the application of a traction force and therefore seems to be unavoidable, it should be controlled and properly limited in order to preserve topsoil structure and reduce erosion. In spite of this recognized need for limiting the slip of tractor tyres, no theoretical approaches have been presented so far to indicate a range of slip values where no topsoil cutting effect occurs.

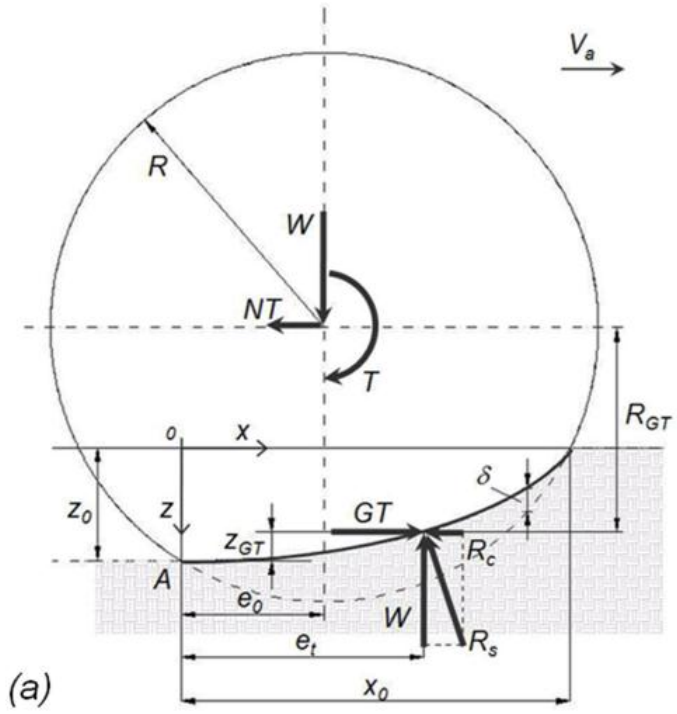

The aim of this paper is to propose a mechanistic approach to define conditions which lead to soil cutting due to slip of tractor tyres. The approach is validated on the basis of field traction tests with a MFWD tractor on an agricultural silt loam (SiL) Calcaric Fluvisol. Indicative limits of slip values not to be exceeded in tillage operations in order to avoid soil cutting effect are suggested for the conditions considered.

\section{MATERIALS AND METHODS}

\section{A. Soil-Tyre Interaction Modelling for a MFWD Tractor}

The stress-strain interaction at soil-tyre contact was analysed by means of a model which simulates traction performance of a deformable wheel (Osetinsky and Shmulevich, 2004; Shmulevich and Osetinsky, 2003).

The main forces acting on the wheel are shown in fig. 2 with a detail of the elementary forces acting at soil-tyre contact.

The model assumes the soil to behave as a plastic nonlinear medium, the wheel to roll in steady-state motion at a low velocity, and the tyre to deformation in linear elasticity.

The soil-tyre contact surface in the longitudinal direction has a parabolic form with the apex at the rear point of contact $A$ (fig. 2), and the wheel-soil interaction is two dimensional (plane-strain problem). This latter assumption implies that the rut depth is the same across the width, and the width is the same along the contact surface, moreover all values are referred to the unit width of the wheel.

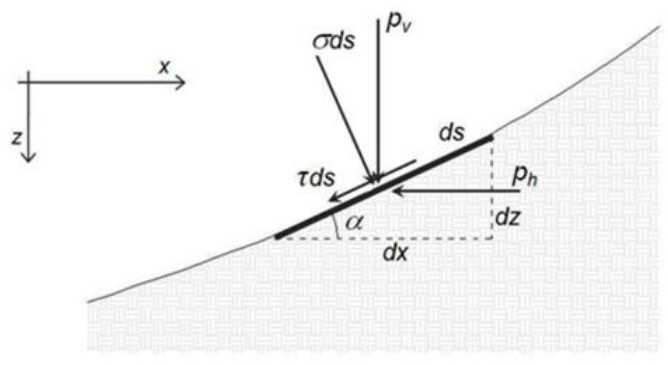

(b)

Figure 2. Interaction bet ween soil and a driven pneumatic wheel $(a)$ with the detail of the elementary forces at soil-tyre contact $(b)$ according to Shmulevich and Osetinsky (2003).

The dynamic wheel load due to load transfer effect was considered on the basis of the equilibriu m condition of the tractor body (fig. 3), as follows:

$$
W_{r}=W_{0, r}+\Delta W
$$

for the front wheel and

$$
W_{f}=W_{0, f}-\Delta W
$$

for the rear wheel.

The terms $W_{0, f}$ and $W_{0, r}$ are the stationary wheel loads on the front wheel and rear wheel respectively, whereas $W_{f}$ and $W_{r}$ are the wheel loads in dynamic conditions on the front wheel and rear wheel respectively. The term $\Delta W$ is the 
difference between the wheel load in stationary and dynamic condition due to the load transfer effect.

According to fig. $3 \Delta W$ is calculated as:

$$
\Delta W=\frac{T_{f}+T_{r}+\left(N T_{f}+N T_{r}\right)\left(h-R_{r, r}\right)+N T_{f}\left(R_{r, r}-R_{r, f}\right)}{L}
$$

in which $T_{f}, N T_{f}, R_{r, f}$ and $T_{r}, N T_{r}, R_{r, r}$ are in order the total driving torque, the net traction and the rolling radius of the front wheel and the rear wheel respectively, $h$ is the height of the drawbar measured on the field in the operating configuration and $L$ is the wheelbase of the tractor.

Equation 3 is derived assuming the rolling radius to be a good approximation of the height of the wheel hub and to be constant, and the rut depth small enough to be neglected in the calculation. Moreover this equation is valid when the pulling force is applied horizontally, which means that the total tractor weight remains constant and only its distribution between the front and rear axles changes.

The multipass effect accounts for the different mechanical behaviour of soil interacting with the front wheel and the rear wheel, this can be considered by means of a differentiated soil mechanical characterization with bevameter tests before tractor passage as well as on the rut left from the passage of the front wheel, according to Bekker (1960).

For a tractor with rigid coupling between the front and the rear axles, the ratio of the theoretical speed of the front

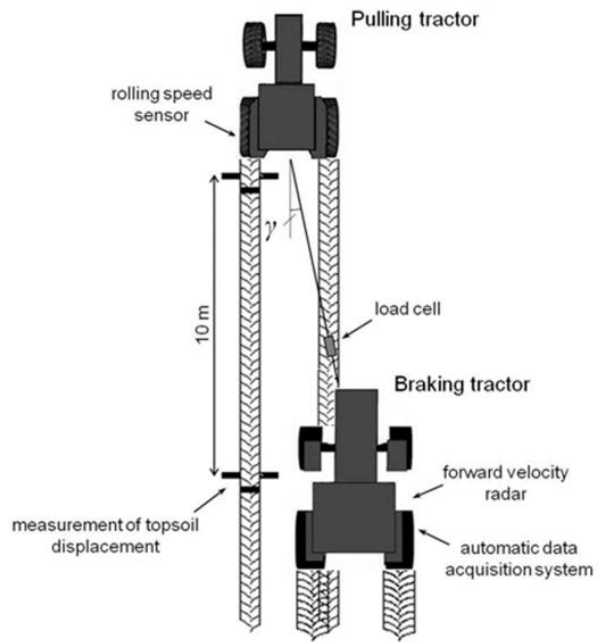

(a) wheel to that of the rear wheel $K_{s}$ is fixed, and therefore there is a precise relationship between the slip of the front wheel $i_{\text {front }}$ and that of the rear wheel $i_{\text {rear }}$ in straight line motion:

$$
i_{\text {front }}=1-\frac{\left(1-i_{\text {rear }}\right)}{K_{s}}
$$

Preliminary tests with the MFWD $65 \mathrm{~kW}$ tractor have indicated values of $K_{s}$ very close to 1 (0.997 and 1.002 respectively with tyre inflation pressures of $160 \mathrm{kPa}$ and 60 $\mathrm{kPa}$ ), allowing a simplified analysis in which the slip of the front wheel and that of the rear wheel are assumed to be the same.

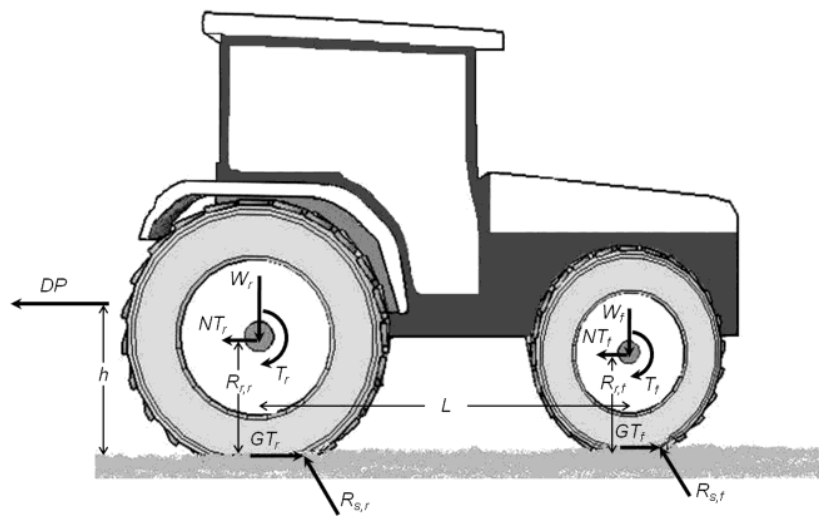

Figure 3. Forces on a MFWD tractor.

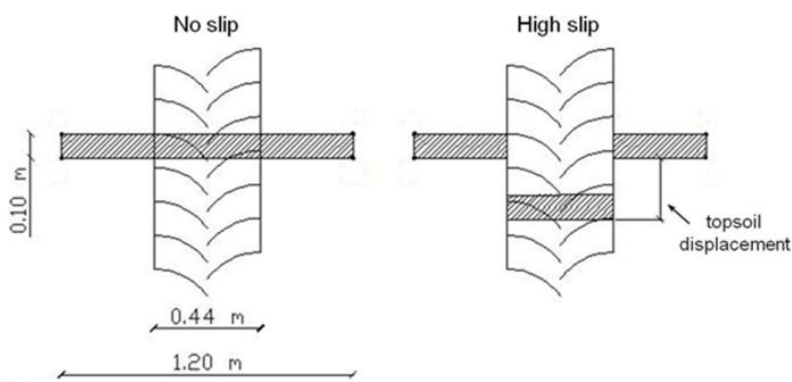

(b)

Figure 4. Layout of the traction test in steady-state motion along a corridor $(a)$ and specification of the system of spray painted strips for the measurement of the topsoil displacement $(a$ and $b$ ).

\section{B. Design of Field Tests}

Field traction tests were carried out on an agricultural silt loam (SiL) Calcaric Fluvisol with maize stubble (fig. 1) in Frauenfeld $(\mathrm{CH})$ [47 $34^{\circ} 32^{\prime}$ N, $8^{\circ} 52^{\prime} 20^{\prime}$ E].

Several corridors $4 \mathrm{~m}$ wide and with a length ranging between $45 \mathrm{~m}$ and $85 \mathrm{~m}$, according to the field geometry, were delimited in the field. Each corridor was driven in steady-state motion in which the slip of the pulling tractor was kept constant by controlling the developed drawbar pull with a braking tractor. The drawbar pull developed was varied from one corridor to the next and consequently also the slip. This latter ranged between $5 \%$ and $48 \%$.

The longitudinal topsoil shear displacement due to tyre slip was chosen as a suitable indicator of the soil cutting effect and measured along the tracks of the pulling tractor after tractor passage. The pulling tractor and the braking tractor did not move in alignment during the test, this allowed the two tractors to have independent tracks and the longitudinal topsoil shear displacement to be measured on a track trafficked by the pulling tractor only. 
In order to measure the longitudinal topsoil shear displacement, a system of strips orthogonal to the tractor track was spray painted on the topsoil surface, around $10 \mathrm{~m}$ apart, before tractor passage. The topsoil shear displacement was measured in each corridor with 2 or 3 repetitions. The layout of the traction test in steady-state motion along a corridor and the specification of the system of spray painted strips for the measurement of the topsoil displacement are sketched in fig. 4. The pulling tractor moved with locked differential in order to obtain the highest traction performance. The drawbar pull in the longitudinal direction was obtained by taking into account the angle $\gamma$ of the steel cable used to connect the two tractors (fig. 4). This angle was around $3^{\circ}$ (in fig. 4 a distorted scale is used).

A MFWD Hürlimann H488 DT tractor of $65 \mathrm{~kW}$ engine power and weighing $40.8 \mathrm{kN}$ was employed as pulling tractor. A John Deere 6920 tractor weighing $66.7 \mathrm{kN}$ was used as braking machine. The drawbar pull was measured by a $200 \mathrm{kN}$ load cell in section with the steel cable used to connect the two tractors, the actual forward velocity was measured by a radar velocity sensor, whereas the wheel rolling velocity was registered by means of a wireless wheel speed sensor (two pulses per wheel revolution) set on a rear wheel of the pulling tractor. All these parameters were recorded and displayed by an automatic acquisition system in the braking tractor. The load acting on the wheels in the stationary condition was measured with a flat bed wheel load scale. The pulling tractor was equipped with 380/85R24 front tyres and 420/85R34 rear tyres. The tyre inflation pressure was measured with a tyre pressure gauge.

The tests were carried out using three configurations, hereinafter referred to as case 1 , case 2 , and case 3 : in case 1 the tyre inflation pressure was set to $60 \mathrm{kPa}$, in case 2 , to $160 \mathrm{kPa}$, whereas in case 3 dual tyres were used, 11.2R28 at the front axle and $11.2 \mathrm{R} 42$ at the rear axle, the inflation pressure was set to $60 \mathrm{kPa}$ and the tractor weight was increased from $40.8 \mathrm{kN}$ to $56.6 \mathrm{kN}$ by means of front and rear ballasts

\section{Characterization of the Topsoil and the Tyres}

Some physical parameters of the agricultural silt loam (SiL) Calcaric Fluvisol chosen as the location for the tests are listed in Table I along with the parameters for the soiltyre interaction model.

TABLE I. SOME CHARACTERISTICS OF THE SILT LOAM SOIL USED IN THE TRACTION PERFORMANCE STUDIES.

\begin{tabular}{lc}
\hline Soil property & $\mathbf{0 - 0 . 1 0 ~} \mathbf{~ m}$ \\
\hline Sand $\left(\mathrm{g} \mathrm{kg}^{-1}\right)$ & 200 \\
Silt $\left(\mathrm{g} \mathrm{kg}^{-1}\right)$ & 530 \\
Clay $\left(\mathrm{g} \mathrm{kg}^{-1}\right)$ & 270 \\
Texture (USDA) & Silt loam $(\mathrm{SiL})$ \\
Soil classification (IUSS Working Group WRB, & Calcaric Fluvisol \\
2006) & 1.33 \\
Dry bulk density $\left(\mathrm{Mg} \mathrm{m}^{-3}\right)$ & 50.1 \\
Total porosity $(\%)$ & 40.2 \\
Volumetric water content $(\%)$ & 1.60 \\
Matric suction $(\mathrm{kPa})$ & 298.2 \\
Cohesive modulus of deformation $K_{c}\left(\mathrm{kN} \mathrm{m}^{-(n+1)}\right)$ & 479.0 \\
Frictionalmodulus of deformation $K_{\varphi}\left(\mathrm{kN} \mathrm{m}^{-(n+2)}\right)$ & 0.778 \\
Exponent of deformation $n$ & 15.9 \\
Cohesion $c(\mathrm{kPa})$ & 25.6 \\
Angle of shear resistance $\varphi\left({ }^{\circ}\right)$ & 0.01 \\
Shear deformation modulus $k(\mathrm{~m})$ & \\
\hline
\end{tabular}

A tractor-mounted bevameter was employed to characterize topsoil mechanical behaviour. An exhaustive description of this bevameter was reported by Diserens and Steinmann (2003).

The vertical plate penetration tests were carried out with two circular plates of $0.2 \mathrm{~m}$ and $0.3 \mathrm{~m}$ in diameter. The values of $K_{c}$ and $K_{\varphi}$ and exponent of deformation $n$ (Table I) were determined according to Wong (1980).

The horizontal plate shear deformation tests were performed by means of an annular plate with an outer diameter of $0.3 \mathrm{~m}$ and an inner diameter of $0.2 \mathrm{~m}$. The soil shear stress-displacement curves were measured at vertical pressure ranging between $21 \mathrm{kPa}$ and $155 \mathrm{kPa}$, and values of $c, \varphi$ and $k$ (Table I) were determined according to Wong (1980).

The vertical plate penetration tests and the horizontal plate shear deformation tests were executed before tractor passage as well as on the rut left from the passage of the front wheel, however, no significant differences in soil mechanical behaviour were observed and therefore a unique characterization was adopted.

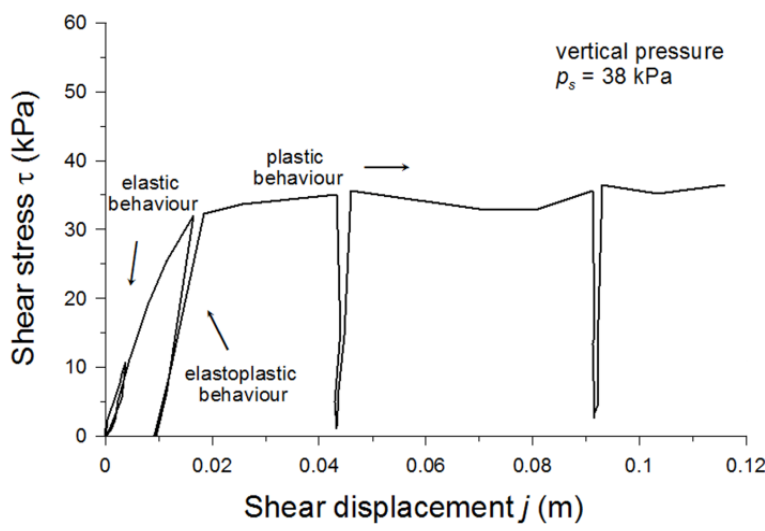

Figure 5. Soil shear stress-displacement curve obt ained in horizontal plate shear deformation test with a bevameter at $38 \mathrm{kPa}$ of vertical pressures with repetitive shearing.

An additional repetitive shearing test at vertical pressure of $38 \mathrm{kPa}$, reported in fig. 5, indicates three main phases of soil behaviour under shear stress: in a first very limited interval of displacements the soil seems to show an elastic behaviour, afterwards the elastic behaviour is associated with plastic deformations in a hardening elastoplastic phase, whereas the last phase is characterized by big plastic deformations under almost constant stress, indicating that soil failure is occurring.

Table II shows some specifications of the tractors used in the traction performance studies for the three cases tested.

The tyre rolling radius $R_{r}$ (Table II) was determined according to ASABE (1983) as the distance travelled per revolution of the wheel divided by $2 \pi$ when operating at the specified zero condition. This latter was here assumed as the vehicle operating in self-propelled condition on a hard surface, such as a smooth road, according to Wismer and Luth (1973). Parameters $K_{\text {carc }}$ and $\Delta K_{p}$ which characterize tyre stiffness were determined on the basis of the tyre specifications as in Lines and Murphy (1991). In case 3 the system of dual tyres was modelled, at least in first approximation, as one tyre having width and stiffness given 
by the sum of those of the two independent tyres.

\section{RESULTS}

The relationship between the drawbar pull developed by the tractor and the slip of tractor wheels is shown in fig. 6 . Here experimental measures are seen alongside the model simulation for the three cases underconsideration.

The highest traction performance in case 3 was due to the use of dual tyres, the tractor ballasting, and besides the low tyre inflation pressure.

In case 1 the use of low tyre inflation pressure turned out in traction performance higher than in case 2. The model simulations showed general good agreement with the experimental results (root mean square error RMSE of 2.71 $\mathrm{kN})$.

Simulations of the geometry of the soil-tyre contact surface and distributions of the normal stress $\sigma$, the shear stress $\tau$ and the soil strength $\tau_{\max }$ along the soil-tyre contact surface are shown in figs. 7 and 8 . For each point of the contact surface, the normal stress and the shear stress are calculated according to Shmulevich and Osetinsky (2003), whilst the soil strength $\tau_{\max }$ is given by the following:

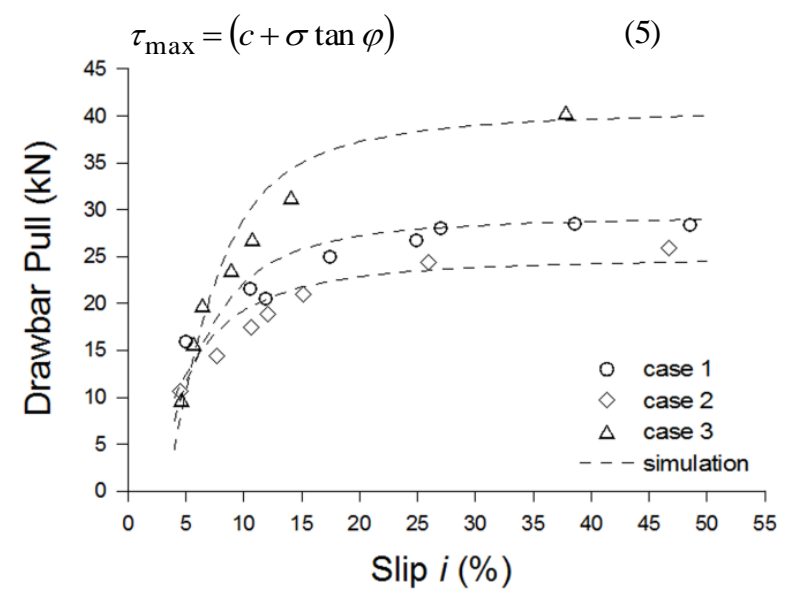

Figure 6. Measured and simulated relationship between drawbar pull and wheel slip for the $65 \mathrm{~kW}$ MFWD tractor in the three configurations considered: (case 1) tractor weight $40.8 \mathrm{kN}$ and tyre inflation pressure 60 $\mathrm{kPa}$; (case 2) tractor weight $40.8 \mathrm{kN}$ and tyre inflation pressure $160 \mathrm{kPa}$; (case 3 ) tractor weight $56.6 \mathrm{kN}$, tyre inflation pressure $60 \mathrm{kPa}$, front and rear dual tyres.

This latter is the soil failure condition under a given normal pressure.

Figure 7 refers to the tractor configuration of case 1 and reports simulations for slip values of $5 \%$ and $15 \%$ for the front wheel (figs. $7 a$ and $7 c$, respectively) and for the rear wheel (figs. $7 b$ and $7 d$, respectively).

The load transfer effect caused the length of the contact surface and the rut depth of the front wheel to decrease as slip increased, with an opposite result for the rear wheel. The maximum normal stress at soil-tyre contact decreased with slip in the front wheel, and increased with slip in the rear wheel.

The shear stress at soil-tyre contact rose sharply with slip. At slip of 5\% it assumed values very far from the soil strength, whereas at slip of $15 \%$ it approached the soil strength over a wide part of the contact surface.

At the rear point of the soil-tyre contact the shear stress was closer to the soil strength, and this latter, according to equation 5 , corresponded to the soil cohesion $c$.

The ratio $t \tau_{\max }$ varied along the contact surface as a function of the soil shear displacement $j$ :

$$
\frac{\tau}{\tau_{\max }}=\left(1-e^{-j / k}\right)
$$

In fig. 8 are reported the simulations of the geometry of the soil-tyre contact surface and the stress distribution at soil-tyre contact of the rear wheel at a slip of $15 \%$ for cases 2 and 3 .

In case 2 the contact surface was shorter and deeper than in case 1 (fig. $7 d$ ), with higher maximum normal stress. In case 3 the contact surface was shorter than in case 1 and longer than in case 2 , and the rut depth resulted close to case 2. The maximum normal stress was lower than in cases 1 and 2.

TABLE II. SOME SPECIFCATIONS OF THE TRACTORS USED IN THE TRACTION PERFORMANCE STUDIES.

\begin{tabular}{|c|c|c|c|c|c|c|}
\hline Braking tractor & \multicolumn{6}{|c|}{ John Deere $6920(110 \mathrm{~kW})$} \\
\hline Pulling tractor & \multicolumn{6}{|c|}{ Hürlimann H488 DT (65 kW) } \\
\hline Wheelbase pulling tractor $\mathrm{L}(\mathrm{m})$ & \multicolumn{6}{|c|}{2.34} \\
\hline & \multirow{2}{*}{\multicolumn{2}{|c|}{ case 1}} & \multicolumn{2}{|c|}{ case 2} & \multicolumn{2}{|c|}{ case 3} \\
\hline Height of the drawbar $h(\mathrm{~m})$ & & & \multicolumn{2}{|c|}{0.83} & \multicolumn{2}{|c|}{0.77} \\
\hline & front axle & rear axle & front axle & rear axle & front axle & rear axle \\
\hline Tyre & $380 / 85 \mathrm{R} 24$ & $420 / 85 R 34$ & $380 / 85 \mathrm{R} 24$ & $420 / 85 \mathrm{R} 34$ & $380 / 85 \mathrm{R} 24$ & 420/85R34 \\
\hline Dual tyre & - & - & - & - & $11.2 \mathrm{R} 28$ & 11.2R42 \\
\hline Stationary wheel load $W_{0}(\mathrm{kN})$ & 9.3 & 11.1 & 9.3 & 11.1 & 11.6 & 16.7 \\
\hline Tyre width $b(\mathrm{~m})$ & 0.38 & 0.44 & 0.38 & 0.44 & $0.38 / 0.29^{*}$ & $0.44 / 0.30$ \\
\hline Tyre unloaded radius $R(\mathrm{~m})$ & 0.63 & 0.79 & 0.63 & 0.79 & $0.63 / 0.63$ & $0.79 / 0.79$ \\
\hline Tyre rolling radius $R_{r}(\mathrm{~m})$ & 0.58 & 0.76 & 0.59 & 0.77 & 0.58 & 0.76 \\
\hline Tyre inflation pressure $P_{\text {in }}(\mathrm{kPa})$ & 60 & 60 & 160 & 160 & $60 / 60$ & $60 / 60$ \\
\hline Rim diameter $D_{\text {rim }}(\mathrm{m})$ & 0.61 & 0.86 & 0.61 & 0.86 & $0.61 / 0.71$ & $0.86 / 1.07$ \\
\hline Tyre stiffness $\left(\mathrm{kN} \mathrm{m}^{-1}\right)$ & 202.8 & 232.0 & 324.8 & 432.2 & $202.8 / 187.7$ & 232.0/198.9 \\
\hline Tyre carcass stiffness $K_{\text {carc }}\left(\mathrm{kN} \mathrm{m}^{-1}\right)$ & 129.5 & 111.8 & 129.5 & 111.8 & $129.5 / 122.4$ & $111.8 / 97.6$ \\
\hline Inflation pressure dependence of the tyre $\Delta K_{p}\left(\mathrm{kNm}^{-1} \mathrm{kPa}^{-1}\right)$ & 1.22 & 2.00 & 1.22 & 2.00 & $1.22 / 1.09$ & $2.00 / 1.69$ \\
\hline
\end{tabular}



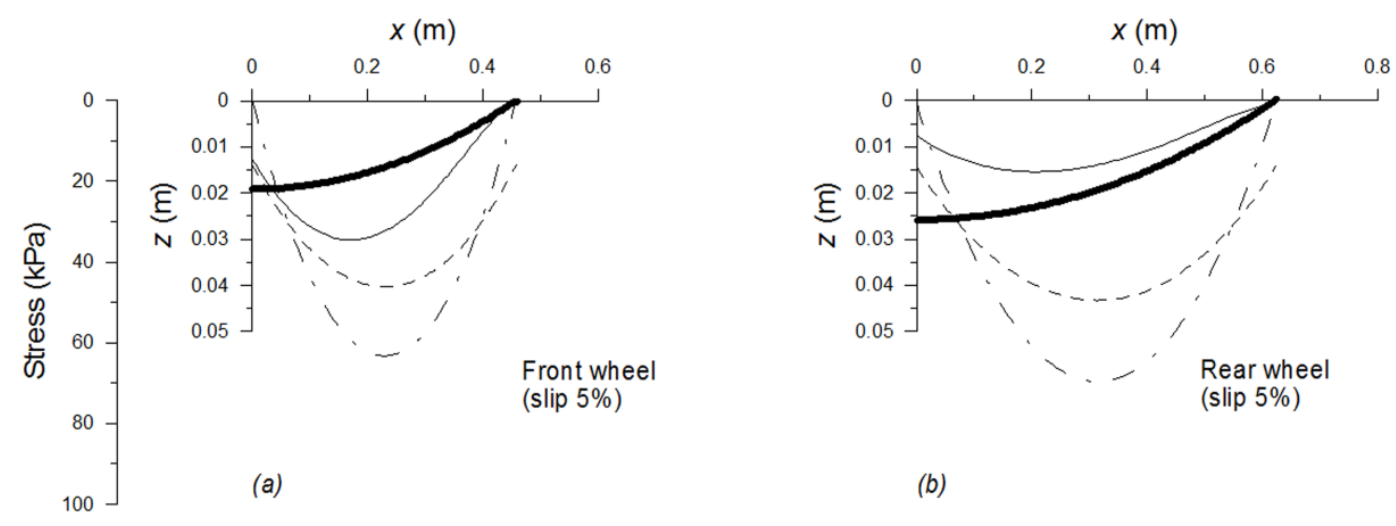

(b)
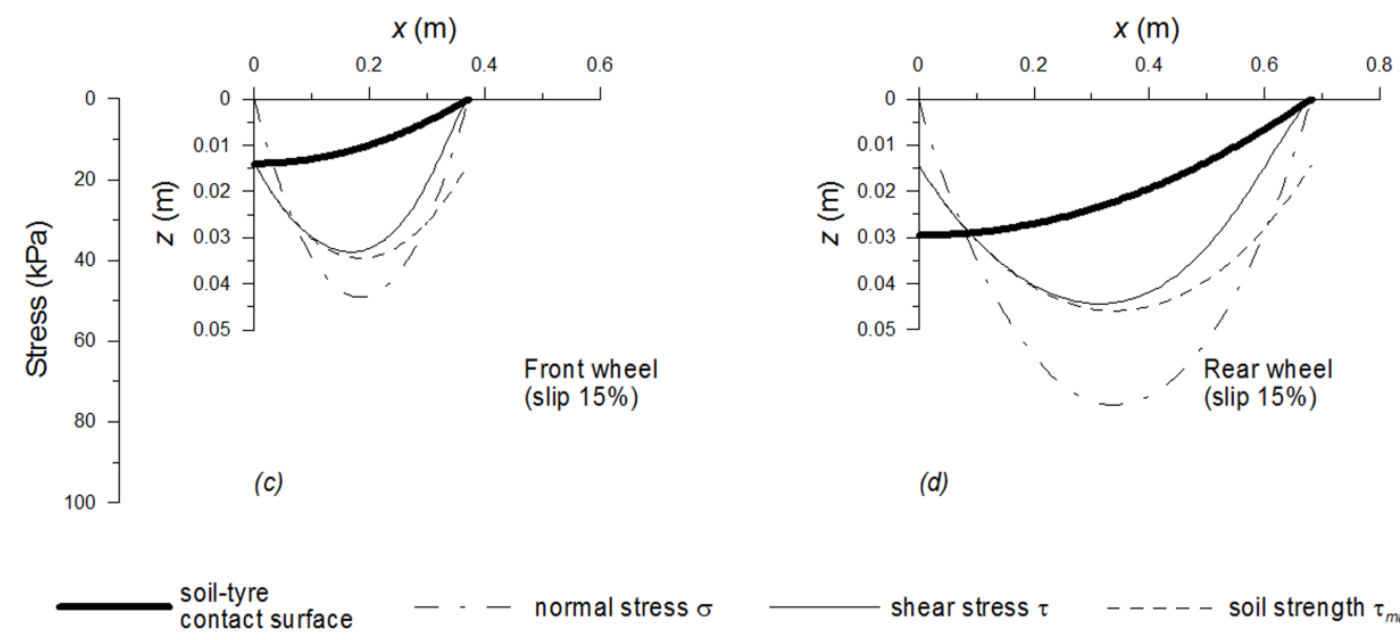

(d)

Figure 7. Soil-tyre contact surface with distribution of normal stress, shear stress and soil strength at slip of $5 \%$ and $15 \%$ for the front and the rear wheels of the $65 \mathrm{~kW}$ MFWD tractor (weight $40.8 \mathrm{kN}$, tyre inflation pressure $60 \mathrm{kPa}$ ): (a) front wheel at slip of $5 \%,(b)$ rear wheel at slip of $5 \%,(c)$ front wheel at slip of $15 \%,(d)$ rear wheel at slip of $15 \%$.
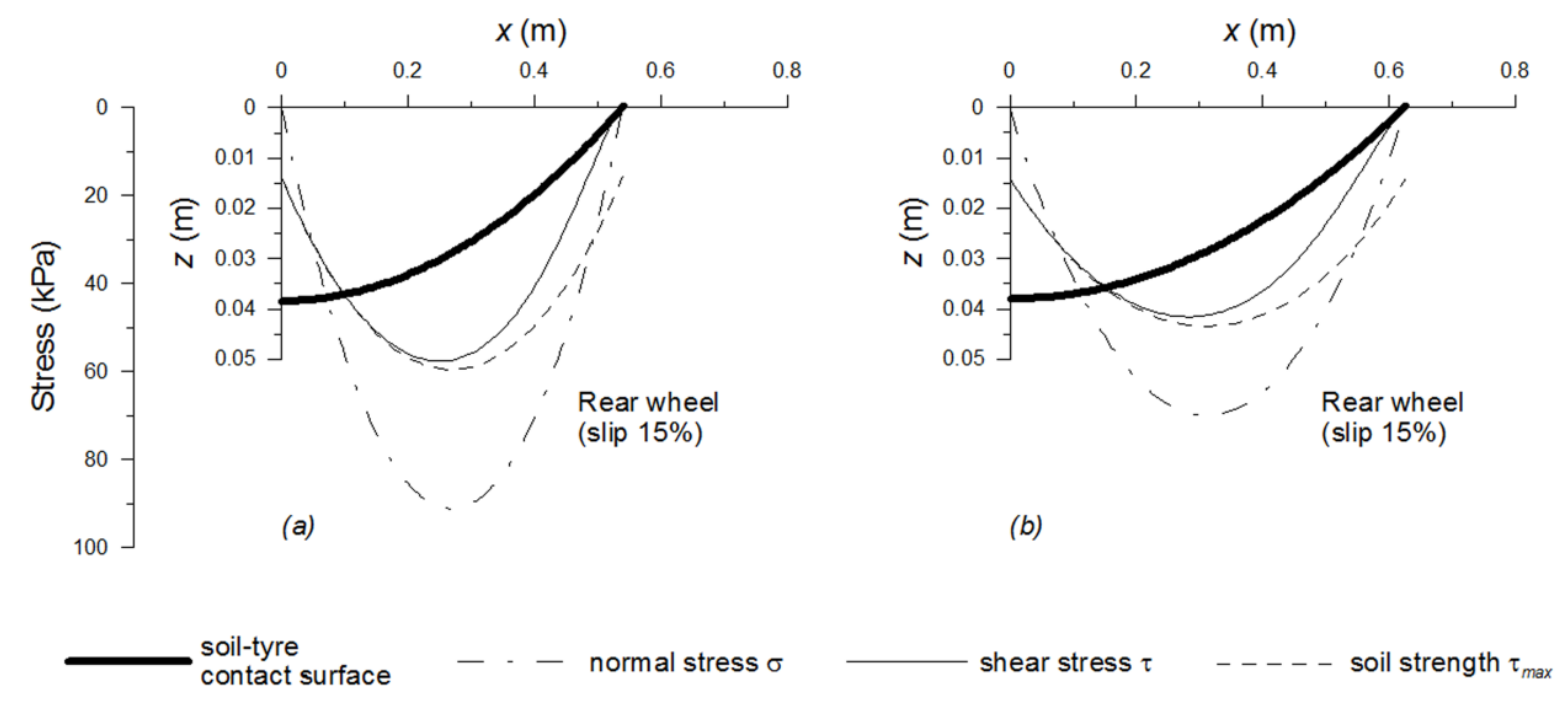

Figure 8. Soil-tyre contact surface with distribution of normal stress, shear stress and soil strength at slip of $15 \%$ for the rear wheel of the $65 \mathrm{~kW}$ MFWD tract or in configurations 2 and $3:(a)$ tractor weight $40.8 \mathrm{kN}$ and tyre inflation pressure $160 \mathrm{kPa} ;(b)$ tractor weight $56.6 \mathrm{kN}$, tyre inflation pressure $60 \mathrm{kPa}$, front and rear dual tyres.

In fig. 9 the soil stress paths along the contact surface with the tyre for the rear wheel in case 1 are represented in terms of mean stress $p=\left(\sigma_{1}+\sigma_{3}\right) / 2$ and deviatoric stress $q=\left(\sigma_{l^{-}}\right.$ $\left.\sigma_{3}\right) / 2$. 


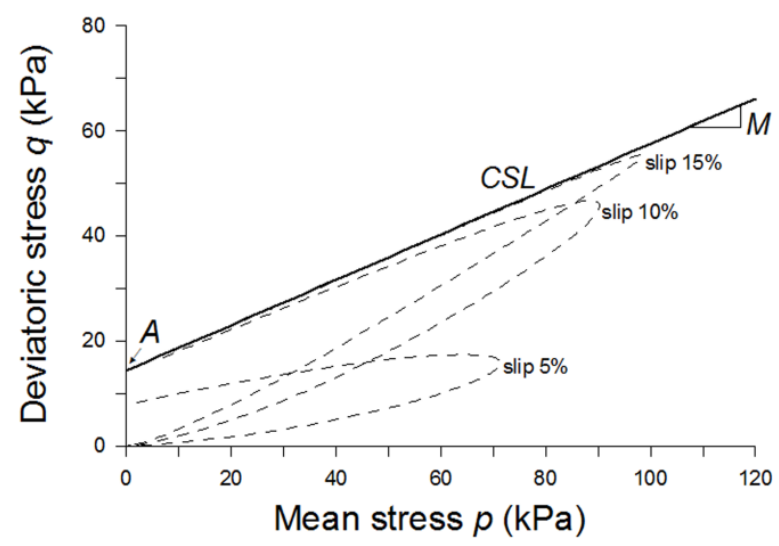

Figure 9. Soil critical state line $C S L$ and stress paths along the soil-tyre contact surface at different slip for the rear wheel of the $65 \mathrm{~kW}$ MFWD tractor (weight $40.8 \mathrm{kN}$, tyre inflation pressure $60 \mathrm{kPa}$ ).

The terms $\sigma_{1}$ and $\sigma_{3}$ are respectively the greatest principal stress and the smallest principal stress which are univocally defined when the tangent plane to each point of the soil-tyre contact surface is assumed as the critical plane, i.e. the plane on which the ratio $\tau \sigma \sigma$ is maximum. Intercept $A$ and slope $M$ of the critical state line $C S L$ were derived as a function of the soil cohesion $c$ and the angle of soil shear resistance $\varphi$ for a plane stress state:

$$
\begin{gathered}
A=c \cos \varphi \\
M=\sin \varphi
\end{gathered}
$$

The stress paths at slip of 5\%,10\% and $15 \%$ indicated that the soil stress state varied significantly along the contact surface and with slip. Moreover, the last point of the stress path which corresponded to the rear contact point turned out to be the closest to the critical state condition. At slip of $15 \%$ a wide part of the soil stress path lay on the critical state line $C S L$, indicating that the critical state condition was fully reached.

Figure 10 shows the evolution of the measured topsoil shear displacement $j$ with slip $i$ for case 1 (fig. $10 a$ ), case 2 (fig. 10b) and case 3 (fig. 10c). This is set alongside the evolution of the maximum ratio between shear stress $\tau$ and soil strength $\tau_{\text {max }}$ for the front and rear wheels.

As long as the shear stress along the contact surface of both the front tyre and the rear tyre with soil was considerably lower than soil strength and consequently the maximum ratio $t \tau_{\max }$ assumed values to a great extent lower than 1, the topsoil shear displace ments measured were very small, moreover they did not vary significantly with slip. When the maximum ratio $t \tau_{\max }$ along the contact surface approached a value of 1 , the topsoil shear displacements measured rose sharply in the three cases under consideration. According to equation 6 the ratio $t \tau_{\max }$ assumes the value 1 as an asymptotic value, however, in practice a ratio $t d \tau_{\max }$ of 0.99 could be regarded as a limit beyond which soil strength is considered entirely mobilized.

Such a limit was reached in case 1 at soil-front tyre contact for slip of $11 \%$ and at soil-rear tyre contact for slip of $13 \%$, in case 2 at both soil-front tyre contact and soil-rear tyre contact for slip of $11 \%$, and in case 3 at both soil-front tyre contact and soil-rear tyre contact for slip of $13 \%$.

\section{DISCUSSION}

Tractor traction tyres interact with soil by a system of normal and tangential stresses along the soil-tyre contact surface, in this interaction the traction force is developed by
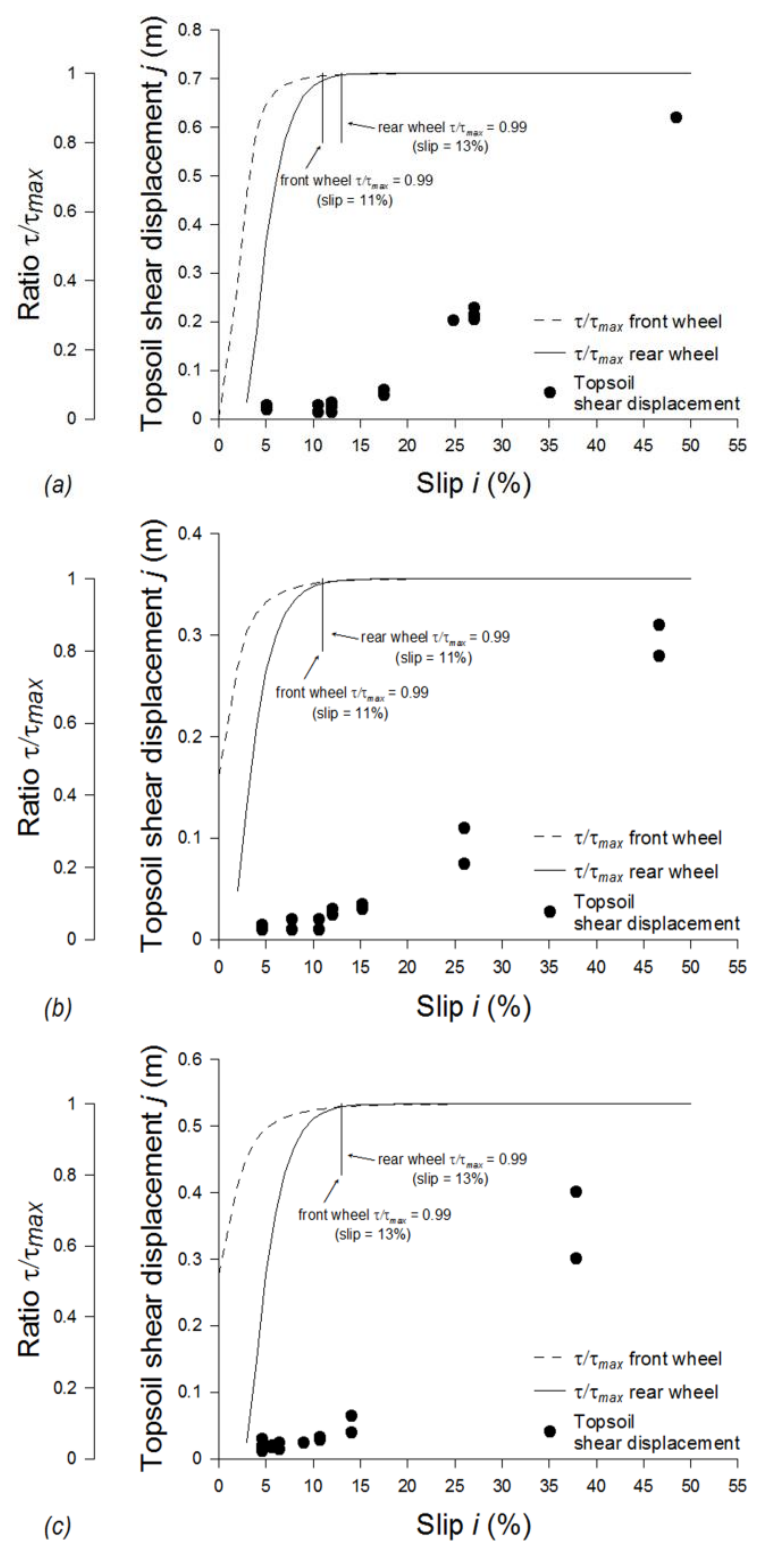

Figure 10. Evolution of topsoil shear displacement with wheel slip compared with theevolution of the maximum ratio $\tau / \tau_{\max }$ with wheel slip for the front wheel and the rear wheel of the $65 \mathrm{~kW}$ MFWD tractor in the three configurations considered: (a) tractor weight $40.8 \mathrm{kN}$ and tyre inflation pressure $60 \mathrm{kPa}$; (b) tractor weight $40.8 \mathrm{kN}$ and tyre inflation pressure $160 \mathrm{kPa}$; (c) tractor weight $56.6 \mathrm{kN}$, tyre inflation pressure $60 \mathrm{kPa}$, front and rear dual tyres.

progressively mobilizing the topsoil strength at contact with tyre, and as soon as the whole strength is mobilized the soil elements among tyre lugs fail (soil cutting), causing topsoil damage. This damage in terms of cutting effect due to slip of tractor tyres has never been properly considered so far (Diserens and Battiato, 2012). 
The analytical approach presented was aimed at defining the mechanical condition at soil-tyre contact under which this topsoil damage occurs, and providing indicative limits of tyre slip for the conditions considered.

The soil-tyre interaction model used as a theoretical framework provided reliable simulations of traction performance in terms of drawbar pull and slip (fig. 6) for the $65 \mathrm{~kW}$ MFWD tractor on the silt loam Calcaric Fluvisol (Table I) in the three configurations considered (Table II).

Simulations of the geometry of the soil-tyre contact surface and the distribution of stresses at soil-tyre contact (figs. 7 and 8) indicated the influence of the tractor configuration, the slip of the wheels and the load transfer effect on the soil stress state at contact with tyre. The shear stress $\tau$ turned out to vary considerably with slip, approaching the soil strength $\tau_{\max }$. The ratio $\tau \tau_{\max }$ varied over the contact surface with tyre as a function of the soil shear displacement $j$ according to equation 6 , and its maximu $m$ value rose sharply with slip as long as a value of 0.99 was reached (fig. 10).

During shear tests the silt loam (SiL) Calcaric Fluvisol considered in this study showed an elastoplastic behaviour with hardening (fig. 5). At low slip the soil was stressed in its domain of hardening behaviour and it deformed when shear stress increased. In this phase the soil was able to provide a high increase in traction force (drawbar pull) corresponding to small variations in slip (fig. 6). The topsoil shear displacements measured were very small in this phase (fig. 10), moreover, in spite of the big increase in traction (fig. 6), they did not vary significantly with slip.

Soil failed as soon as its strength was approached, exhibiting a rise in topsoil shear displacements (fig. 10). This condition may occur at different but close slip values for the soil-front tyre contact and the soil-rear tyre contact (fig. 10). Once the soil strength was approached at the rear point of the soil-tyre contact, the traction force (drawbar pull) continued to increase with slip because the available soil strength was progressively mobilized on more extended areas of the contact surface (figs. 7 and 8), but its gradient was greatly reduced (fig. 6).

The value of the ratio $t \tau_{\max }$ of 0.99 proved to be an indicative limit, suitable for practice, beyond which soil cutting is expected to occur (fig. 10). This limit is reached at a certain slip of the tyre which depends on soil mechanical behaviour and tyre characteristics such as dimensions, rolling radius, carried load, inflation pressure, and stiffness. In the traction tests presented, the ratio $t \tau_{\max }$ of 0.99 was reached at first at soil-front tyre contact for slip of $11 \%$ when the tyre inflation pressure was set to $60 \mathrm{kPa}$ (fig. 10a), at both soil-front tyre contact and soil-rear tyre contact for slip of $11 \%$ when the tyre inflation pressure was set to 160 $\mathrm{kPa}$ (fig. 10b), and at both soil-front tyre contact and soilrear tyre contact for slip of $13 \%$ when dual tyres were used at front and rear axles, the tractor was ballasted (from 40.8 $\mathrm{kN}$ to $56.6 \mathrm{kN}$ ), and the tyre inflation pressure was set to 60 $\mathrm{kPa}$ (fig. 10c).

The elastic phase of soil behaviour, which might precede the elastoplastic phase according to fig. 5, was not observable in the range of slip considered.

The choice of the tractor configuration is a matter of primary importance in tillage operations for the optimization of traction performance, i.e. limiting slip of the wheels which involves a significant energy loss. To a great extent this aspect affects the fuel consumption and the time required for soil tillage. Moreover, as pointed out in this study, limiting slip concurs in the preservation of the topsoil. From this point of view, the limit values of slip obtained for the silt loam (SiL) Calcaric Fluvisol in the three tractor configurations should be regarded as indicative limits not to be exceeded in field operations in order to avoid soil cutting effect in the conditions considered.

\section{CONCLUSIONS}

High slip of tractor traction tyres causes topsoil damage in terms of soil cutting effect with the formation of a strengthless layer strongly exposed to erosion and an underlying layer where shear deformations contribute to the alteration of soil structure functionalities. The soil cutting effect was clearly indicated by longitudinal topsoil shear displacement. This latter turned out not to vary significantly at low slip. As soon as the soil strength was approached topsoil shear displacement rose, indicating that soil cutting was occurring.

A ratio $t \tau_{\max }$ of 0.99 , as a maximum value along the soil-tyre contact surface, was identified as the indicative limit beyond which soil cutting is expected to occur. This limit corresponds to a certain tyre slip which depends on soil mechanical behaviour and tyre characteristics such as dimensions, rolling radius, carried load, inflation pressure, and stiffness.

In the traction tests presented, a ratio $t \tau_{\max }$ of 0.99 was reached at first at soil-front tyre contact for slip of $11 \%$ when the tyre inflation pressure was set to $60 \mathrm{kPa}$ (case 1), and at both soil-front tyre contact and soil-rear tyre contact for slip of $11 \%$ when the tyre inflation pressure was set to $160 \mathrm{kPa}$ (case 2), and for slip of $13 \%$ when dual tyres were used at front and rear axles, the tractor was ballasted (from $40.8 \mathrm{kN}$ to $56.6 \mathrm{kN}$ ), and the tyre inflation pressure was set to $60 \mathrm{kPa}$ (case 3).

These slip values should be regarded as indicative limits not to be exceeded in tillage operations in order to avoid soil cutting effect in the conditions considered.

\section{ACKNOWLEDGMENT}

The authors wish to acknowledge the Swiss Federal Office for the Environment FOEN and the tyre manufacturer Michelin for the financial support for this study.

\section{REFERENCES}

Alaoui, A., Lipiec, J., Gerke, H.H. 2011. A review of the changes in the soil pore system due to soil deformation: A hydrody namic perspective. Soil \& Tillage Research 115$116,1-15$. 
ASABE. 1983. Agricultural En gineers Yearbook of Standards, ASAE Standard S296.2 - Uniform terminology for traction of agricultural tractors, self-propelled implements, and other traction and transport devices. American Society of Agricultural and Biological Engineers.

Bekker, M.G. 1956. Theory of Land Locomotion. University of Michigan Press. Ann Arbor, MI.

Bekker, M.G. 1960. Off-the-Road Locomotion. University of Michigan Press. Ann Arbor, MI.

Berisso, F.E., Schjønning, P., Lamande', M., Weisskopf, P., Stettler, M., Keller, T. 2013. Effects of the stress field induced by a running ty re on the soil pore system. Soil \& Tillage Research 131, 36-46.

Davies, D.B., Finney, J.B., Richardson, S.J. 1973. Relative effects of tractor weight and wheel-slip in causing soil compaction. Journal of Soil Science 24, 399-409.

Diserens, E., Battiato, A. 2012. Traction force in arable farming: Agronomic and environmental aspects after field-data acquisition and modelling. In: International Conference of Agricultural Engineering, CIGR-AgEng, June 8-12, Valencia, Spain.

Diserens, E., Steinmann, G. 2003. In-situ determination of the fracture point of an agricultural soil using the plate penetration test, comparison with the oedometer method and validation. In: Proceedings of the International Conference on Geo-Environmental Engineering. Singapore. Pp.: 93-106.

Fan, J.C., Wu, M.F. 2001. Effects of soil strength, texture, slope steepness and rainfall intensity on interrill erosion of some soils in Taiwan. In: Stott, D.E., Mohtar, R.H., Steinhardt, G.C. (Eds.), Sustaining the Global Farm, Selected papers from the 10th International Soil Conservation Organization Meeting. Pp.: 588-593.

Horn, R. 2003. Stress-strain effects in structured unsaturated soils on coupled mechanical and hydraulic processes," Geoderma 116, 77-88.

IUSS Working Group WRB. 2006. World reference base for soil resources 2006. Report No. 103, Food and Agriculture Organization of the United Nations. Rome.

Janosi, Z., Hanamoto, B. 1961. The analytical determination of drawbar pull as a function of slip for tracked vehicles in deformable soils," in: Proceedings of the 1st International Conference on the Mechanics of SoilVehicle Systems, Edizioni Minerva Tecnica. Torino. Pp. 707-736.
Kirby, J.M. 1991. The influence of soil deformations on the permeability to air. Journal of Soil Science 42, 227-235.

Lines, J.A., Murphy, K. 1991. The stiffness of agricultural tractor tyres," Journal of Terramechanics 28, 49-64.

Nearing, M.A., West, L.T. 1988. Soil strength indices as indicators of consolidation. American Society of Agricultural Engineers 31, 471-476.

O’Sullivan, M.F., Robertson, E.A.G., Henshall, J.K. 1999. Shear effects on gas transport in soil. Soil \& Tillage Research $50,73-83$.

Olsen, H.J. 1988. Effect of shear stress on soil compaction. Report 124. Swedish University of Agricultural Science, Department of Agricultural Engineering. Uppsala.

Osetinsky, A., Shmulevich, I. 2004. Traction performance simulation of a pushed/pulled driven wheel. Transactions of the ASAE 47, 981-994.

Raghavan, G.S.V,. McKyes, E., Chassé, M. 1977. Effect of wheel slip on soil compaction. Journal of Agricultural Engineering Research 22, 79-83.

Raghavan, G.S.V., McKyes, E., Beaulieu, B. 1978. Clay soil compaction due to wheel slip. Transactions of the ASAE 21, 646-649.

Shmulevich, I., Osetinsky, A. 2003. Traction performance of a pushed/pulled drive wheel. Journal of Terramechanics 40 35-50.

Watson, D.A., Laflen, J.M. 1986. Soil strength, slope and rainfall effects of interrill erosion. Transactions of the ASAE 29, 98-102.

Wills, B.M.D. 1963. The measurement of soil shear strength and deformation moduli and a comparison of the actual and theoretical performance of a family of rigid tracks. Journal of A gricultural En gineering Research 8, 115-131.

Wismer, R.D., Luth, H.J. 1973. Off-road traction prediction for wheeled vehicles. Journal of Terramechanics 10, 49-61.

Wong, J.Y. 1980. Data processing methodology in the characterization of the mechanical properties of terrain Journal of Terramechanics 17, 13-41.

Wong, J.Y., Preston-Thomas, J. 1983. On the characterization of the shear stress-displacement relationship of terrain. Journal of Terramechanics 19, 225-234.

Yong, R.N., Fattah, E.A., Skiadas, N. 1984. Vehicle traction mechanics. Elsevier Science. Amsterdam. 